DOI: $10.22481 /$ recuesb.v8i14.7852

\title{
PROJETO SABERES NO ENFRENTAMENTO AO CORONAVÍRUS - INFORMAÇÃO EM TEMPO DE PANDEMIA - RELATO DE EXPERIÊNCIA
}

\author{
PROJECT KNOWLEDGE IN COMBATING THE CORONAVIRUS - INFORMATION \\ IN TIME OF PANDEMIA - EXPERIENCE REPORT
}

Greicy Cristine Kosvoski ${ }^{1}$

Helena Fornari Basso ${ }^{2}$

Margarete Dulce Bagatini ${ }^{3}$

Resumo: Objetivando disseminar informações verídicas e atualizadas sobre a COVID-19 e a atual pandemia em qual o mundo se encontra, foi institucionalizado em março de 2020 o "Projeto saberes no enfrentamento ao coronavírus", na Universidade Federal da Fronteira Sul (UFFS), executado por acadêmicos de medicina e enfermagem do campus Chapecó, e coordenado por uma professora da instituição. Usufruindo de parcerias anteriormente estabelecidas, a proposta teve como intuito prevenir, orientar, atualizar e divulgar informações verídicas em relação ao novo coronavírus de cunho técnico-científico e que proporcionassem fácil entendimento aos leitores. O público-alvo, definido previamente entre a coordenação do projeto e as parcerias externas, foram os moradores, pacientes, alunos, professores e demais profissionais de um determinado bairro do município de Chapecó-SC, e por recomendações dos órgãos de saúde, estabeleceram-se atividades/divulgações de maneira remota através de redes sociais. As atividades foram organizadas e divididas para que as publicações pudessem seguir um cronograma e atingir o maior número de pessoas possíveis, com qualidade e segurança, e assim fez-se, ao final de 3 meses de projeto, houve diversos bairros do município de Chapecó, diferentes cidades do estado de Santa Catarina, 7 estados do Brasil e 12 países distintos alcançados. Contribuindo, desse modo, para a disseminação de conteúdos confiáveis em quantidade e qualidade significativa, ajudando a informar, atualizar e orientar a população sobre o novo coronavírus.

Palavras-chave: Coronavírus. Saúde global. Educação. Redes sociais online. Acesso à informação.

\footnotetext{
${ }^{1}$ Graduanda do curso de Enfermagem, pela Universidade Federal da Fronteira Sul (UFFS), Campus Chapecó, Chapecó, Santa Catarina, Brasil. Bolsista do projeto de extensão Saberes no Enfrentamento ao Coronavírus. Orcid: 0000-0002-3400-446X E-mail: greicykosvoski@ outlook.com

${ }^{2}$ Graduanda do curso de Enfermagem, pela Universidade Federal da Fronteira Sul (UFFS), Campus Chapecó, Chapecó, Santa Catarina, Brasil. Bolsista do projeto de extensão Saberes no Enfrentamento ao Coronavírus. Orcid: 0000-0003-0653-3601 E-mail: helenafornari@ hotmail.com

${ }^{3}$ Farmacêutica. Doutora em Ciências Biológicas (Bioquímica Toxicológica). Docente da Universidade Federal da Fronteira Sul (UFFS), Campus Chapecó, Chapecó, Santa Catarina, Brasil. Orcid: 0000-0001-9263-4980 E-mail: margaretebagatini@yahoo.com.br
} 
Abstract: Aiming to disseminate truthful and updated information about COVID-19 and the current pandemic in which the world finds itself, the "Knowledge project in the fight against the coronavirus" was institutionalized in March 2020 at the Federal University of Fronteira Sul (UFFS), carried out by academics of medicine and nursing at the Chapecó campus and coordinated by a professor at the institution. Taking advantage of previously established partnerships, the proposal was intended to prevent, guide, update, and disseminate information in relation to the new coronavirus, which had a technical-scientific nature, veracity and which provided easy understanding for readers. The target audience, previously defined between the coordination of the project and external partnerships, was residents, patients, students, teachers and other professionals from a certain neighborhood in the municipality of Chapecó$S C$ and based on recommendations from health agencies, established themselves activities / disclosures remotely, through social networks. The activities were organized and divided so that the publications could follow a schedule and thus reach the largest number of people possible, with quality and safety, and so it was done, at the end of 3 months of the project, there were several neighborhoods in the city. municipality of Chapeco, different cities in the state of Santa Catarina, 7 states in Brazil and 12 different countries reached. Contributing to the dissemination of content in quantity and quality, helping to inform, update and guide the population about the new coronavirus.

Keywords: Coronavirus. Global health. Education. Online Social Networking. Access to Information.

\section{Introdução}

O novo coronavírus surgiu em dezembro de 2019, em Wuhan, capital da província de Hubei na China, identificado como a principal causa de pneumonias, sendo inicialmente denominado como 2019-nCoV. A posteriori, esse novo vírus foi nomeado pelo Comitê Internacional de Taxonomia de Vírus (ICTV) como coronavírus tipo 2 da síndrome respiratória aguda grave (SARS-CoV-2), e a Organização Mundial da Saúde (OMS) definiu como padrão a Doença de Coronavírus 2019, chamada então COVID-19. Ainda, a OMS anunciou a epidemia no dia 30 de janeiro de 2020, devido aos aspectos da COVID-19 constituírem uma Emergência de Saúde Pública de Importância Internacional (ESPII), em 11 de março de 2020, foi declarada pandemia devido à alta taxa de contágio (JIN et al., 2020; OLIVEIRA et al., 2020; PASCARELLA et al., 2020; PASCOAL et al., 2020).

Desde a sua descoberta, o novo coronavírus se tornou uma ameaça mundial à saúde, até

$$
\begin{array}{l|l}
\multirow{2}{*}{\text { REVISTA }} & \text { EXTENSÃO \& CIDADANIA } \\
\cline { 2 - 3 } & \text { v. 8, n. 14, p. 490-502, jul./dez. 2020. ISSN 2319-0566 }
\end{array}
$$


dia 12 de outubro de 2020, a COVID-19 causou 1.079.029 mortes no mundo inteiro e infectou 37.704.153 indivíduos, em um total de 253 países/áreas/territórios. Dentre os países com maiores casos confirmados estão os Estados Unidos da América (EUA), Índia e Brasil com 7.682.128, 7.175.880 e 5.094.979, respectivamente (WORLD HEALTH ORGANIZATION, 2020). As investigações sobre a fonte de disseminação e transmissão do SARS-CoV-2 ainda são incertas, estudos sugerem que o morcego Rhinolophus affinis é o hospedeiro natural do SARS-CoV-2, devido à similaridade de 96,2\% dos genomas, além disso, a transmissão do vírus de um animal para um humano requer um hospedeiro intermediário, nesse sentido foi proposto que os pangolins são os hospedeiros intermediários da SARS-CoV-2 (ESAKANDARI et al., 2020; PASCARELLA et al., 2020).

Os sintomas da COVID-19 tendem a aparecer após um período de aproximadamente cinco a sete dias de incubação do vírus no organismo humano (ROTHAN; BYRAREDDY, 2020). Alguns indivíduos se mantêm assintomáticos, já outros podem apresentar sintomas mais comuns como tosse, febre e falta de ar, outros sintomas relatados são fraqueza, mal-estar, dificuldade respiratória, dores musculares, dor de garganta, perda do paladar e/ou olfato e conjuntivite. Aproximadamente $80-90 \%$ dos casos são assintomáticos, ou manifestam sintomas leves e apenas 5\% dos casos são críticos, podendo ocasionar pneumonia com insuficiência pulmonar, síndrome do desconforto respiratório agudo (SDRA), se agravando posteriormente para insuficiência de múltiplos órgãos com consequências fatais (ESAKANDARI et al., 2020; PASCARELLA et al., 2020; SALZBERGER et al., 2020).

O principal modo de transmissão de humano para humano é através de gotículas respiratórias contaminadas, como tosse, espirros e contato direto com mucosas da boca, olhos e nariz, a transmissão também pode ocorrer no contato indireto com superfícies e objetos de pessoas infectadas. As gotículas podem alcançar até dois metros, e não permanecem no ar, mas o SARS-CoV-2 é viável em aerossóis por até três horas. Destaca-se que no período de incubação o vírus também pode ser transmitido, dessa forma, pacientes assintomáticos são potenciais fontes de transmissão. Além disso, a presença do SARS-CoV-2 foi detectada em amostras de fezes, porém não há evidências de transmissão fecal-oral (ESAKANDARI et al., 2020; PASCOAL et al., 2020; ZHENG, 2020).

$$
\begin{array}{l|l}
\multirow{2}{*}{\text { REVISTA }} & \text { EXTENSÃO \& CIDADANIA } \\
\cline { 2 - 3 } & \text { v. 8, n. 14, p. 490-502, jul./dez. 2020. ISSN 2319-0566 }
\end{array}
$$


O diagnóstico ocorre através de métodos moleculares, sorologia e cultura viral, sendo que o teste de RT-PCR (reação em cadeia da polimerase com transcrição reversa) é um método molecular regularmente usado para diagnóstico, sendo usadas amostras do trato respiratório superior por meio de swabs nasofaríngeo ou orofaríngeo. Já em pacientes intubados, utiliza-se amostra do trato respiratório inferior (tubo endotraqueal ou lavagem broncoalveolar). Ainda, recomendam-se exames radiológicos $(\mathrm{RX})$ do tórax ou tomografia computadorizada (TC), pois são ferramentas importantes no diagnóstico da COVID-19, devido às características nos achados, que incluem distribuição bilateral de sombras irregulares e opacidade de vidro fosco (NASERGHANDI; ALLAMEH; SAFFARPOUR, 2020; PASCARELLA et al., 2020; TU et al., 2020; ZHENG, 2020).

Após exposição ao vírus, os testes sorológicos identificam a resposta imunológica dos indivíduos mostrando se a infecção é recente ou tardia, por meio da produção de imunoglobulinas $\mathrm{M}(\operatorname{IgM})$ e imunoglobulinas $\mathrm{G}(\mathrm{IgG})$, em que $\operatorname{IgG}$ representa uma memória imunológica e IgM uma primeira linha de defesa, sendo produzida logo após a infecção. Portanto, quando ocorre a detecção de IgM no soro, revela-se uma exposição recente ao vírus, enquanto a detecção de IgG sugere que a exposição ocorreu vários dias/semanas antes. Além disso, leva-se em média duas semanas ou mais após a infecção para que os anticorpos sejam detectados (DI MAURO et al., 2020; ESAKANDARI et al., 2020).

Em relação ao tratamento da COVID-19, segundo a OMS, existem mais de 169 vacinas em desenvolvimento, sendo que 26 delas estão em fases de testes em humanos. Além disso, a OMS está trabalhando em parceria com cientistas, empresas e organizações globais de saúde por meio do Acelerador de Acesso às Ferramentas COVID-19 (ACT) para acelerar o desenvolvimento, produção e o acesso equitativo aos testes, tratamentos e vacinas, a fim de acabar com a pandemia (WHO, 2020).

Diante dos fatos, incertezas e conhecimentos da COVID-19, no Brasil, o Ministério da Saúde (MS) criou estratégias que visam diminuir as Fakes News através de aplicativos como o Coronavírus-SUS e um canal de WhatsApp, a fim de evitar a disseminação e propagação massiva de notícias falsas, diminuir o agravamento da situação, de modo que a população fique bem informada com conteúdos reais e confiáveis, sem enganação, manipulação e indução a

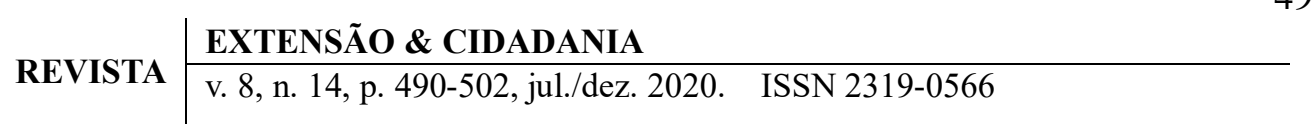


erros (OLIVEIRA et al., 2020). As redes sociais estão presentes na vida de quase todos os indivíduos no contexto atual gerando interações, trocas afetivas e de saberes entre as pessoas, agindo como agente facilitador do compartilhamento de informações. Além disso, tem como característica a agilidade e facilidade para as comunicações entre os diferentes públicos de diferentes locais (GUIMARÃES; MACHADO DIAS; ARGENTO, 2017).

Através da Universidade Federal da Fronteira Sul (UFFS), foi lançado um edital de Apoio Institucional às Ações de Extensão em Saúde para Prevenção Monitoramento e Segurança Frente à Pandemia do Coronavírus, o qual incentivava a elaboração de ações voltadas à COVID-19. Assim, foi elaborado o "Projeto saberes no enfrentamento ao coronavírus", com o objetivo de informar, esclarecer e debater ações de prevenção ao novo coronavírus com alunos, professores, usuários e demais pessoas do bairro São Pedro-Caic (Chapecó-SC), contribuindo para a disseminação de informações, conteúdos e assuntos relevantes, atingindo um maior número de pessoas com qualidade e segurança. Portanto, o objetivo deste artigo é relatar o desenvolvimento do projeto vivenciada pelas bolsistas.

\section{Metodologia}

Trata-se de um estudo descritivo, do tipo relato de experiência, que descreve ações do "Projeto saberes no enfrentamento ao coronavírus". A proposta foi elaborada e aprovada em março de 2020, através da UFFS, campus Chapecó-SC e começou a ser executada em abril. Atualmente, é realizada por uma professora coordenadora e 8 acadêmicos dos cursos de enfermagem e medicina, sendo 6 voluntários e 2 bolsistas.

O projeto possui como metas principais, informar, esclarecer e debater ações de prevenção e combate ao coronavírus responsável pela COVID-19, aproximando os alunos, professores, usuários e demais pessoas do bairro São Pedro-Caic, permitindo que eles multipliquem e disseminem as informações e os conhecimentos de forma segura e confiável. Para que esse objetivo fosse alcançado, dentre as atividades propostas, estava a realização de oficinas na Escola Municipal Básica Victor Meirelles em parceria com o Centro de Saúde da Família São Pedro-Caic, ambos localizados no Bairro São Pedro-Caic, na cidade de Chapecó

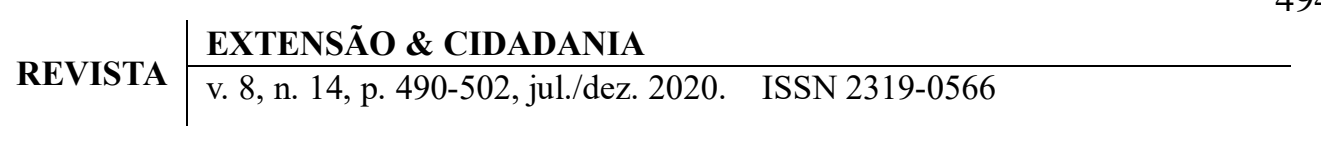


- SC, porém, devido às orientações dos governos estaduais e federais para isolamento e distanciamento social e a suspensão das aulas presenciais, essas oficinas foram adiadas. Para dar andamento, o projeto utilizou a tecnologia como meio de disseminação de informações, elaborando uma página no Facebook (rede social com maior abrangência em meio o público alvo), intitulada "Projeto saberes no enfrentamento ao coronavírus", para realizar orientações e publicações voltadas às temáticas do novo coronavírus, evitando propagação de notícias falsas (Fake News), incompletas ou sem fundamentação.

O projeto estabeleceu publicações nas segundas-feiras, quartas-feiras, sextas-feiras e aos sábados, com o intuito de padronizar a quantidade e os dias de lançamento de conteúdos, facilitando assim uma interação com o público de maneira organizada. Nas postagens, foi possível encontrar boletins epidemiológicos, notícias, informações e atualizações de conteúdos verídicos, com embasamento teórico-científico, podendo ser de nível nacional, internacional, regional ou municipal. As postagens eram em forma de imagem, escrita e legenda referenciada, utilizando uma linguagem clara, elaboradas pelos acadêmicos e publicadas pelas bolsistas. As criações, depois de enviadas para o e-mail do projeto, passavam por avaliação de conteúdo, fonte e linguagem utilizada, havendo, posteriormente, orientações de ajustes, se necessário, estes organizados e coordenados pela professora e pelas bolsistas. Dessa forma, o projeto buscou oferecer informações verdadeiras, de fácil compreensão, que possam oferecer mais segurança ao público na realização das atividades e tomadas de decisões que envolvam o vírus/doença/pandemia.

\section{Resultados e discussão}

No decorrer dos 4 meses (abril, maio, junho e julho) de projeto, foram desenvolvidas diversas publicações abordando diferentes aspectos em relação ao novo coronavírus, os quais contribuíram para que toda a população pudesse se manter bem informada em relação ao contexto atual da pandemia. Além disso, o projeto elaborou publicações voltadas para o funcionando dos serviços de saúde da cidade de Chapecó-SC, como hospitais, postos de campanha, Centro de Saúde da Família (CSF), Centro de Triagem Médica para que, assim,

$$
\begin{array}{l|l}
\multirow{2}{*}{\text { REVISTA }} & \text { EXTENSÃO \& CIDADANIA } \\
\cline { 2 - 3 } & \text { v. 8, n. 14, p. 490-502, jul./dez. 2020. ISSN 2319-0566 }
\end{array}
$$


todos soubessem onde procurar auxílio médico quando necessário. Ao todo foram 47 temas conforme a Tabela 1, que está organizada em ordem crescente de publicação:

Tabela 1: Assuntos abordados nas publicações do Facebook.

1. Diferença entre isolamento, quarentena, distanciamento e lockdown;

2. Uso adequado da máscara;

3. Sintomas da COVID-19;

4. Cuidados a serem tomados quando sair de casa;

5. Mitos e verdades sobre o Coronavírus;

6. Formas de transmissão do COVID-19;

7. Quando tempo o vírus sobrevive em diferentes superfícies;

8. Como se proteger/prevenir do COVID-19;

9. Higienização adequada das mãos;

10. Grupos de risco do Coronavírus;

11. Alimentos que auxiliam na imunidade;

12. Diferença entre surto, epidemia, pandemia e endemia;

13. Desenvolvimento de vacinas;

14. Importância de se vacinar contra a gripe;

15. Higienização, descarte e tempo de utilização das máscaras (pano, TNT e cirúrgica);

16. Cuidados a serem tomados durante o isolamento em casa em pessoas positivas para COVID19 ;

17. Diferença/relação entre Coronavírus, COVID-19 e Sars-CoV-2;

18. Relação entre a oferta e a demanda dos recursos hospitalares;

19. Por que não abaixar a máscara quando conversar com outras pessoas;

20. Por que o álcool $70 \%$ é mais eficaz como bactericida do que o álcool $46 \%$ e o absoluto;

21. Saúde mental durante o período de pandemia; 
22. Malefícios do automedicamento;

23. A partir de que idade começar a usar máscara?;

24. Eficiência da água e sabão para a lavagem das mãos;

25. COVID-19 pode ser congênito?;

26. O vírus passa pela amamentação?;

27. Como evitar desinformação em tempos de Coronavírus?;

28. Quantos dias em média levam para aparecer os sintomas?;

29. Pessoas assintomáticas podem transmitir o vírus?;

30. Estimativa de subnotificação de casos da COVID-19 no estado de Santa Catarina;

31. Teste da vacina para COVID-19 no Brasil;

32. Ambulatórios de campanha em Chapecó;

33. Métodos laboratoriais para diagnóstico da COVID-19;

34. COVID-19 pode atingir outros órgãos?;

35. O que acontece com o pulmão da pessoa infectada pelo Coronavírus?;

36. Testes rápidos utilizados na COVID-19;

37. Hábitos de vida saudáveis durante a pandemia;

38. O frio é propício para a disseminação da COVID-19?;

39. Impactos na saúde de quem se recupera da forma grave da doença;

40. Perda de olfato e paladar;

41. Lugares com maiores chances de contaminação;

42. Diferença entre gripe, resfriado, tuberculose pulmonar e COVID-19;

43. Orientações para uso do transporte coletivo;

44. Quem já teve COVID-19 pode ter a doença novamente?

45. Relação entre tabagismo e Coronavírus;

46. Endereço, telefone, e-mail e horário de atendimento das Unidades de Saúde de Chapecó; 
47. Relatório semanal de número de casos, óbitos e recuperados (Mundo, Brasil, Santa Catarina e Chapecó).

Fonte: Elaborado pelas autoras.

Durante as ações do projeto, os resultados alcançados de 21 de abril de 2020 até 31 de julho de 2020 foram de 69 publicações e 510 curtidas e seguidores na página do Facebook. O público alcançado se expandiu para além do determinado inicialmente, atingindo um grupo de pessoas de demais bairros do município de Chapecó, de outras cidades da região, alguns estados além de Santa Catarina, como Rio Grande do Sul; Paraná; São Paulo; Mato Grosso; Mato Grosso do Sul e Espírito Santo. Além do alcance nacional, ocorreu alcance internacional, sendo que no exterior o alcance chegou aos Estados Unidos da América; Índia; Paraguai; África do Sul; Portugal; República Dominicana; Argentina; Paquistão; Espanha; Itália; Bolívia e México. Esse alcance foi além do proposto, e de acordo com o intuito de atingir uma vasta população com informações confiáveis e verídicas, observou-se uma repercussão muito positiva.

A partir das diversas publicações, obtivemos o número total de 562 pessoas visualizando a página, já o número de pessoas alcançadas com as publicações foram de 7.489 pessoas, sendo $65 \%$ mulheres e $35 \%$ homens (Gráfico 1), este número é equivalente às pessoas que viram qualquer uma das suas publicações pelo menos uma vez. Em relação ao alcance total de pessoas nas publicações, os números foram de 21.581, sendo que essas pessoas visualizaram as publicações mais de uma vez. Portanto, a média de pessoas alcançadas foi de 312 pessoas sobre todas as publicações. 
Gráfico 1: Porcentagem de pessoas alcançadas com o Facebook conforme faixa etária.

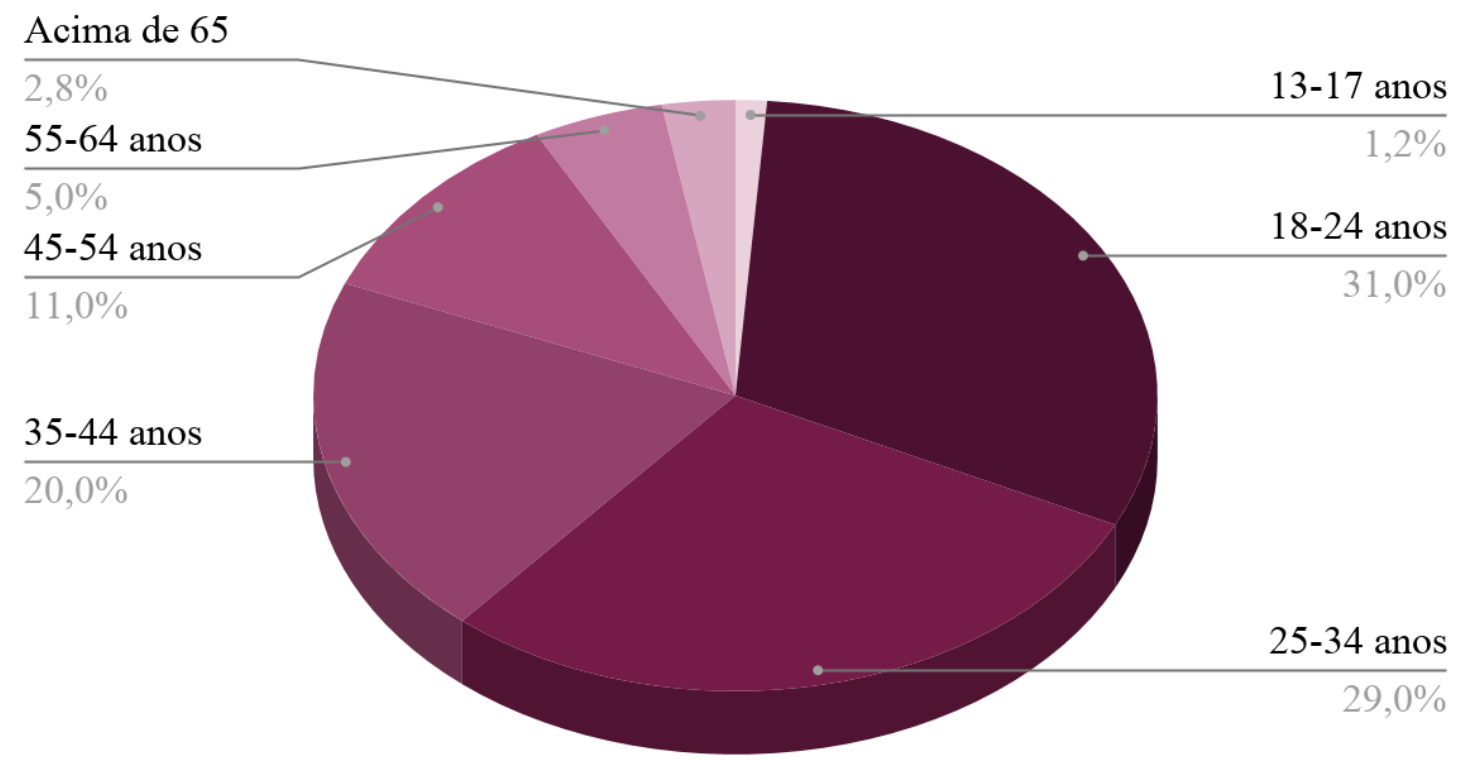

Fonte: Elaborado pelas autoras.

Em relação às postagens, a atualização do boletim epidemiológico publicado no dia 23 de maio de 2020 obteve o maior alcance, chegando ao total de 1.136 pessoas, 28 curtidas e 10 compartilhamentos. A segunda publicação com maior alcance foi no dia 3 de junho de 2020, com o tema sobre o uso correto das máscaras e como elas diminuem a propagação do vírus, chegando ao total de 972 pessoas alcançadas, 42 curtidas e 13 compartilhamentos. A terceira publicação com maior alcance foi realizada no dia 30 de maio de 2020 com a publicação da atualização do boletim epidemiológico, teve um alcance de 785 pessoas, 24 curtidas e 5 compartilhamentos.

Dessa forma, com o aumento das fakes news, desinformação e infodemia, é possível afirmar que as publicações contribuíram positivamente para que as pessoas que leram as informações evitassem a dissipação e propagação de informações falsas, que trazam prejuízos a saúde do coletivo. Também, reduziu a velocidade e o alastramento de notícias e informações

$$
\begin{array}{l|l}
\multirow{2}{*}{\text { REVISTA }} & \text { EXTENSÃO \& CIDADANIA } \\
\cline { 2 - 3 } & \text { v. 8, n. 14, p. 490-502, jul./dez. 2020. ISSN 2319-0566 }
\end{array}
$$


que contribuíssem para o descrédito da ciência e das instituições de saúde, as quais buscam elucidar a população sobre as novas atualidades e informações, evitando o enfraquecimento a adesão da população aos serviços e aos cuidados de saúde diante da pandemia.

\section{Conclusão}

Os resultados alcançados pelo Projeto saberes no enfrentamento ao coronavírus até o presente momento foram de expressiva relevância para a disseminação de conteúdos confiáveis em significativa quantidade e qualidade, visto que os posts continham informações com fontes referenciadas, averiguadas e seguras. Com a possibilidade de curtir, compartilhar, seguir e comentar todo o conteúdo da página no Facebook, de maneira orgânica obteve-se um alcance de 21.581 pessoas, podendo essas ter curtido e visualizado mais de uma vez, e 7.489 pessoas no total, com uma média de 312 alcances por publicação.

Dessa forma, nas redes sociais, principalmente no Facebook em que há uma propagação imensa de notícias e muitas vezes também de fake news, o projeto foi capaz de superar esses obstáculos impostos pelo mundo digital e assim informar, atualizar e orientar uma vasta população, com diferentes idades, de diversas localidades, ajudando a impedir a dissipação de notícias falsas e desatualizadas, que pudessem agravar a situação atual ou até mesmo deixar a população mais assustada.

\section{Referências}

DI MAURO, G. et al. SARS-Cov-2 infection: Response of human immune system and possible implications for the rapid test and treatment. International Immunopharmacology, v. 84, 2020. Disponível em:

https://www.sciencedirect.com/science/article/pii/S1567576920309309. Acesso em: 21 set. 2020.

ESAKANDARI, H. et al. A comprehensive review of COVID-19 characteristics. Biological procedures online, v. 22, n. 19, p. 1-10, 2020. Disponível em: https://biologicalproceduresonline.biomedcentral.com/articles/10.1186/s12575-020-00128-2. Acesso em: 20 set. 2020.

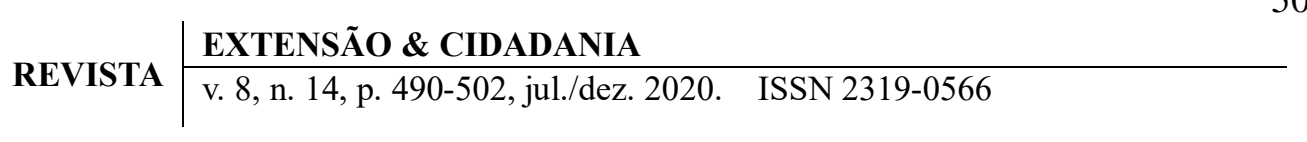


GUIMARÃES, A. L.; MACHADO DIAS, A. C.; ARGENTO, H. Redes sociais e educação: repensando metodologias e estratégias de ensino-aprendizagem. CONGRESSO INTERNACIONAL ABED DE EDUCAÇÃO A DISTÂNCIA, $23^{\circ}$ ENCONTRO, 2017. Anais... 2017. Disponível em: http://www.abed.org.br/congresso2017/trabalhos/pdf/241.pdf. Acesso em: 15 out. 2020.

JIN, Y. et al. Virology, Epidemiology, Pathogenesis, and Control of COVID-19. Viruses, v. 12, p. 1-17, 2020. Disponível em: https://pubmed.ncbi.nlm.nih.gov/32230900/. Acesso em: 10 out. 2020 .

NASERGHANDI, A.; ALLAMEH, S. F.; SAFFARPOUR, R. All about COVID-19 in brief. New Microbes and New Infections, v. 35, 2020. Disponível em:

https://www.journals.elsevier.com/new-microbes-and-new-infections/. Acesso em: 13 out. 2020.

OLIVEIRA, W. K. DE et al. Como o Brasil pode deter a COVID-19. Epidemiol. Serv. Saúde, v. 29, n. 2, p. e2020044, 2020. Disponível em: https://www.scielosp.org/article/ress/2020.v29n2/e2020044/. Acesso em: 12 out. 2020.

PASCARELLA, G. et al. COVID-19 diagnosis and management: a comprehensive review. Journal of Internal Medicine, v. 288, n. 2, p. 192-206, 2020. Disponível em: https://pubmed.ncbi.nlm.nih.gov/32348588/. Acesso em: 30 set. 2020.

PASCOAL, D. B. et al. Síndrome Respiratória Aguda: uma resposta imunológica exacerbada ao COVID19. Brazilian Journal of Health Review, v. 3, n. 2, p. 2978-2994, 2020.

Disponível em:

https://www.researchgate.net/publication/340581504_Sindrome_Respiratoria_Aguda_uma_re sposta_imunologica_exacerbada_ao_COVID19_Acute_Respiratory_Syndrome_an_exacerbat ed_immune_response_to_COVID19. Acesso em: 18 set. 2020.

ROTHAN, H. A.; BYRAREDDY, S. N. The epidemiology and pathogenesis of coronavirus disease (COVID-19) outbreak. Journal of Autoimmunity, v. 109, n. February, 2020. Acesso em: https://www.sciencedirect.com/science/article/abs/pii/S0896841120300469. Acesso em: 21 set. 2020.

SALZBERGER, B. et al. Epidemiology of SARS-CoV-2 infection and COVID-19. Internist, v. 61, n. 8, p. 782-788, 2020. Disponível em: https://pubmed.ncbi.nlm.nih.gov/32548652/.

Acesso em: 18 set. 2020.

TU, Y. F. et al. A review of sars-cov-2 and the ongoing clinical trials. International Journal of Molecular Sciences, v. 21, n. 7, p. 1-19, 2020. Disponível em: https://www.mdpi.com/14220067/21/7/2657. Acesso em: 13 out. 2020. 
WORLD HEALTH ORGANIZATION. O impulso para uma vacina COVID-19.

Disponível em: https://www.who.int/emergencies/diseases/novel-coronavirus-2019/covid-19vaccines. Acesso em: 21 set. 2020.

WORLD HEALTH ORGANIZATION. WHO Coronavirus Disease (COVID-19)

Dashboard. Disponível em: https://covid19.who.int/. Acesso em: 13 out. 2020.

ZHENG, J. SARS-coV-2: An emerging coronavirus that causes a global threat. International Journal of Biological Sciences, v. 16, n. 10, p. 1678-1685, 2020. Disponível em: https://pubmed.ncbi.nlm.nih.gov/32226285/. Acesso em: 12 out. 2020.

Recebido em: 20 de outubro de 2020.

Aceito em: 5 de dezembro de 2020. 